Revue d'histoire du XIXe siècle

Société d'histoire de la révolution de 1848 et des

révolutions du XIXe siècle

39 | 2009

Le monde de l'imprimé: des territoires aux acteurs -

Education et politique - Histoires politiques

\title{
Louis Sébastien MERCIER, Néologie, texte établi, annoté et présenté par Jean-Claude Bonnet
}

Collection Littérature et politique, Paris, Belin, 2009, 592 p. ISBN :

978-2-7011-4271-5. 26 euros

\section{Nicole Edelman}

\section{(2) OpenEdition}

\section{Journals}

Édition électronique

URL : http://journals.openedition.org/rh19/3942

DOI : $10.4000 /$ rh 19.3942

ISSN : $1777-5329$

Éditeur

La Société de 1848

Édition imprimée

Date de publication : 10 décembre 2009

Pagination : 149-150

ISSN : 1265-1354

Référence électronique

Nicole Edelman, « Louis Sébastien MERCIER, Néologie, texte établi, annoté et présenté par JeanClaude Bonnet », Revue d'histoire du XIXe siècle [En ligne], 39 | 2009, mis en ligne le 26 mars 2010, consulté le 22 septembre 2020. URL : http://journals.openedition.org/rh19/3942 ; DOI : https:// doi.org/10.4000/rh19.3942

Ce document a été généré automatiquement le 22 septembre 2020.

Tous droits réservés 


\section{Louis Sébastien MERCIER, Néologie, texte établi, annoté et présenté par Jean-Claude Bonnet}

Collection Littérature et politique, Paris, Belin, 2009, 592 p. ISBN :

978-2-7011-4271-5. 26 euros

\section{Nicole Edelman}

1 La Néologie est un des derniers grands ouvrages de Louis Sébastien Mercier (1740-1814), cet « hérétique en littérature » comme il aimait se présenter. Elle fut publiée en 1801 avec pour sous-titre: Vocabulaire des mots nouveaux, à renouveler, ou pris dans des acceptions nouvelles et n'avait jamais été republiée depuis. La présente édition est donc bienvenue et fort complète. Le texte de Louis Sébastien Mercier est en effet encadré par une présentation éclairante et érudite écrite par Jean-Claude Bonnet, directeur de recherche au CNRS, qui rédige également tout un appareil de notes accompagnant les mots de l'ouvrage, une liste des auteurs et des œuvres cités ainsi que des entrées auxquelles ils apparaissent, enfin quelques annexes et deux comptes rendus d'époque de Néologie, l'un du Mercure de France, l'autre de La Décade philosophique, littéraire et politique.

2 Néologie est donc un dictionnaire, mais de facture très originale; il comporte près de 300 entrées qui sont loin d'être toutes des néologismes, rédigées par l'auteur lui même ou faites de citations. Il est précédé d'une longue introduction écrite par Louis Sébastien Mercier, «d'une vigueur étonnante » comme la qualifie Jean-Claude Bonnet dans son propre texte. Ce dernier nous rappelle que le débat à propos de la néologie n'est pas nouveau puisqu'il s'inscrit dans la querelle des Anciens et des Modernes. D'un côté, une vulgate puriste avait prétendu fixer la langue en donnant pour modèle celle du classicisme, de l'autre bien des auteurs continuaient à créer des mots et ceux-ci finirent par l'emporter. Une grande activité se manifesta ainsi dans bien des dictionnaires du XVIII ${ }^{e}$ siècle. Quant à Louis Sébastien Mercier, il est déjà néologue dans son Tableau de Paris et son Nouveau Paris, glanant toutes sortes de mots chez les piétons de la capitale. Toutefois sa Néologie est d'une autre envergure. Louis Sébastien 
Mercier a pour ambition d'accroître les richesses de la langue française et fait des écrivains « les maîtres exclusifs" du langage (p. XXII) car " tous les grands écrivains ont été Néologues » (p. 8). Il écrit dans son introduction : «j'ai osé, bravant de vaines et passagères clameurs, envisageant la langue telle qu'on l'a parlée, telle qu'on la parlera sans doute un jour, ou telle enfin qu'on devrait la parler ; j'ai osé, dis-je, certain de son prochain et long triomphe, déployer sur ses plus hautes tours l'oriflamme de la Néologie» (p.4). L'auteur définit et redéfinit ainsi bien des mots anciens mais il en invente d'autres avec un plaisir évident. Donnons quelques exemples :

«Abhorrir. Avoir en horreur, en haine. Peut-on Abhorrir ce que l'on a aimé ? »

4 «Egoïser. Parler de soi un peu trop. On ne saurait reprocher à l'auteur du fameux Compte rendu (M. Necker), que de trop Egoïser. Tout poète Egoïse avec plus ou moins d'adresse. Un égoïste n'est pas toujours un Egoïseur; il se voile mieux ». On pourrait encore glaner: Hypocriser, Monoculiste, Politiquer, Profusionner, Tourmenteux ou encore... Zoïliser.

À notre tour de feuilleter avec plaisir ce dictionnaire, qui dépasse cependant ce genre d'ouvrage : Néologie nous découvre en effet aussi une histoire de la langue française, de sa lexicographie et dresse un portrait en creux de son auteur Louis Sébastien Mercier. 